Supplement of Atmos. Chem. Phys., 22, 2333-2349, 2022

https://doi.org/10.5194/acp-22-2333-2022-supplement

(C) Author(s) 2022. CC BY 4.0 License.

(c) (1)

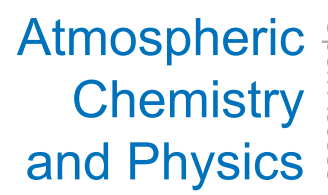

Supplement of

\title{
Biogeochemical and biophysical responses to episodes of wildfire smoke from natural ecosystems in southwestern British Columbia, Canada
}

Sung-Ching Lee et al.

Correspondence to: Sung-Ching Lee (sungching.lee@geog.ubc.ca)

The copyright of individual parts of the supplement might differ from the article licence. 


\section{Supplement}

Table S1. The daily averages of sensible heat flux $(H)$, latent heat flux $(L E)$ and net ecosystem exchange (NEE) at the forest and wetland sites during the smoke events and sunny days, respectively, in 2015, 2017, 2018, and 2020.

\begin{tabular}{|l|l|l|l|l|l|l|l|l|l|}
\hline \multicolumn{7}{|c|}{ Buckley Bay forest site } \\
\hline \multicolumn{2}{|c|}{2015} & \multicolumn{2}{|c|}{2017} & \multicolumn{2}{c|}{2018} & \multicolumn{2}{c|}{2020} \\
\cline { 2 - 10 } & Smoky & Sunny & Smoky & Sunny & Smoky & Sunny & Smoky & Sunny \\
\hline \multirow{2}{*}{ LE } & 147.06 & 159.44 & 90.52 & 121.33 & 80.56 & 102.23 & 25.32 & 46.40 \\
\hline \multirow{2}{*}{ NEE } & 56.40 & -0.44 & 0.46 & -1.53 & 0.80 & -1.25 & -0.82 & -1.73 & -1.90 \\
\hline & & & 43.97 & 29.47 & 20.19 & 24.26 & 30.44 & 49.94 \\
\cline { 2 - 10 } & Smoky & Sunny & Smoky & Sunny & Smoky & Sunny & Smoky & Sunny \\
\hline$H$ & 64.16 & 41.70 & 35.60 & 56.48 & 39.43 & 66.05 & 27.64 & 43.80 \\
\hline LE & 97.42 & 72.15 & 68.69 & 84.77 & 61.56 & 87.59 & 24.35 & 36.01 \\
\hline NEE & -2.89 & -1.59 & -2.38 & -1.09 & -1.15 & -1.23 & -0.43 & -0.76 \\
\hline
\end{tabular}


Table S2. Proportions of variation in gross primary production (GPP) residuals explained by the three environmental variables. The proportions explained by diffuse fraction (DF) were obtained from the $\mathrm{R}^{2}$ values from simple linear regressions that include only DF. The proportions explained by a combination of air temperature $\left(T_{\mathrm{a}}\right)$ and vapor pressure deficit (VPD) were obtained from the difference in $\mathrm{R}^{2}$ values between the simple linear regressions and multiple linear regressions that include all three variables.

\begin{tabular}{|c|c|c|c|c|}
\hline \multicolumn{5}{|c|}{ Buckley Bay forest site } \\
\hline & 2015 & 2017 & 2018 & 2020 \\
\hline $\mathrm{DF}$ & $53 \%$ & $19 \%$ & $89 \%$ & $41 \%$ \\
\hline$T_{\mathrm{a}} \& \mathrm{VPD}$ & $34 \%$ & $38 \%$ & $6 \%$ & $19 \%$ \\
\hline \multicolumn{5}{|c|}{ Burns Bog wetland site } \\
\hline & 2015 & 2017 & 2018 & 2020 \\
\hline DF & $84 \%$ & $44 \%$ & $35 \%$ & $55 \%$ \\
\hline$T_{\mathrm{a}} \& \mathrm{VPD}$ & $12 \%$ & $8 \%$ & $9 \%$ & $6 \%$ \\
\hline
\end{tabular}




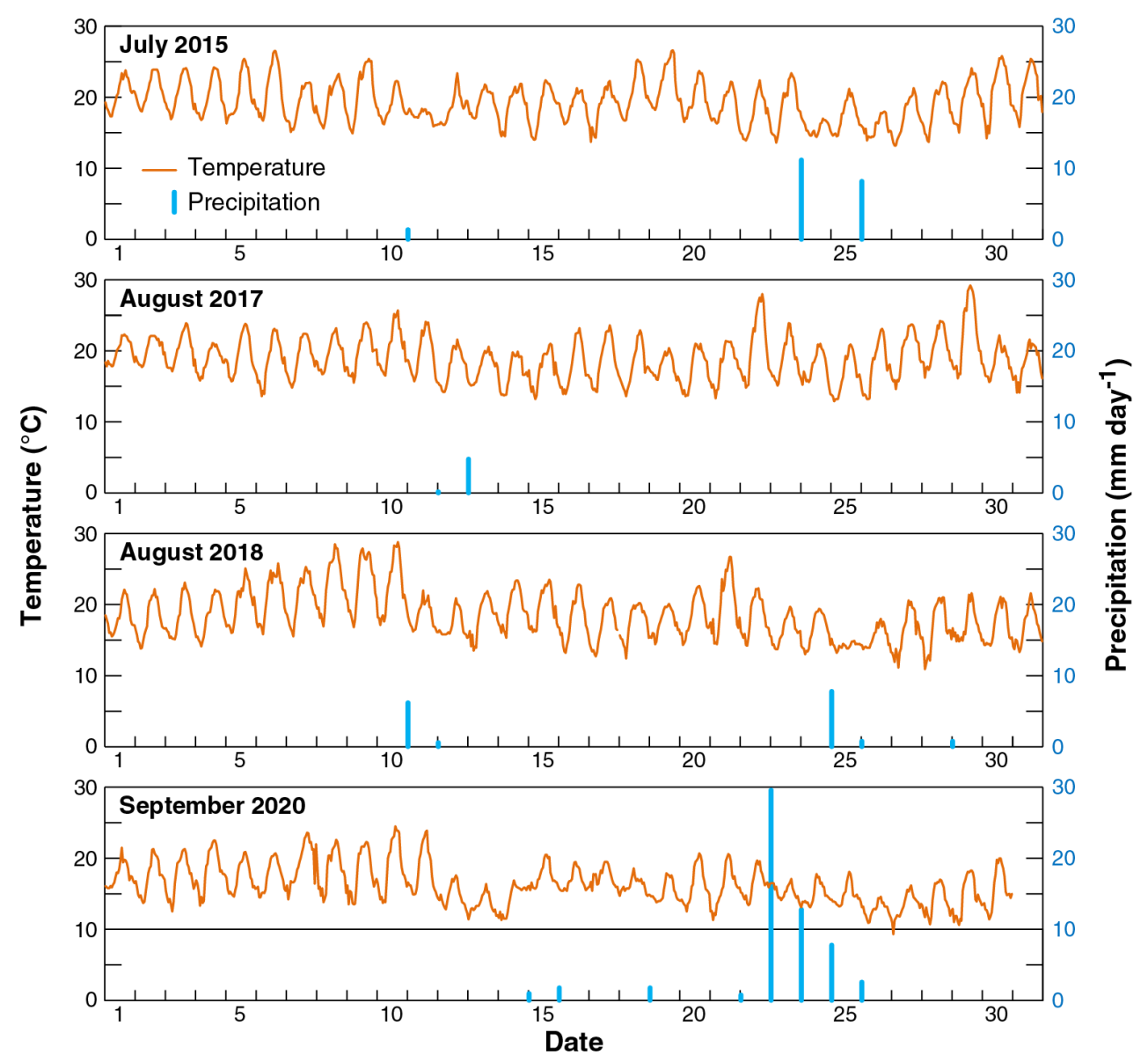

Figure S1. Hourly air temperature and daily precipitation over the wildfire smoke episodes in 2015, 2017, 2018, and 2020 at Buckley Bay (the forest site) and at Burns Bog (the wetland site). 

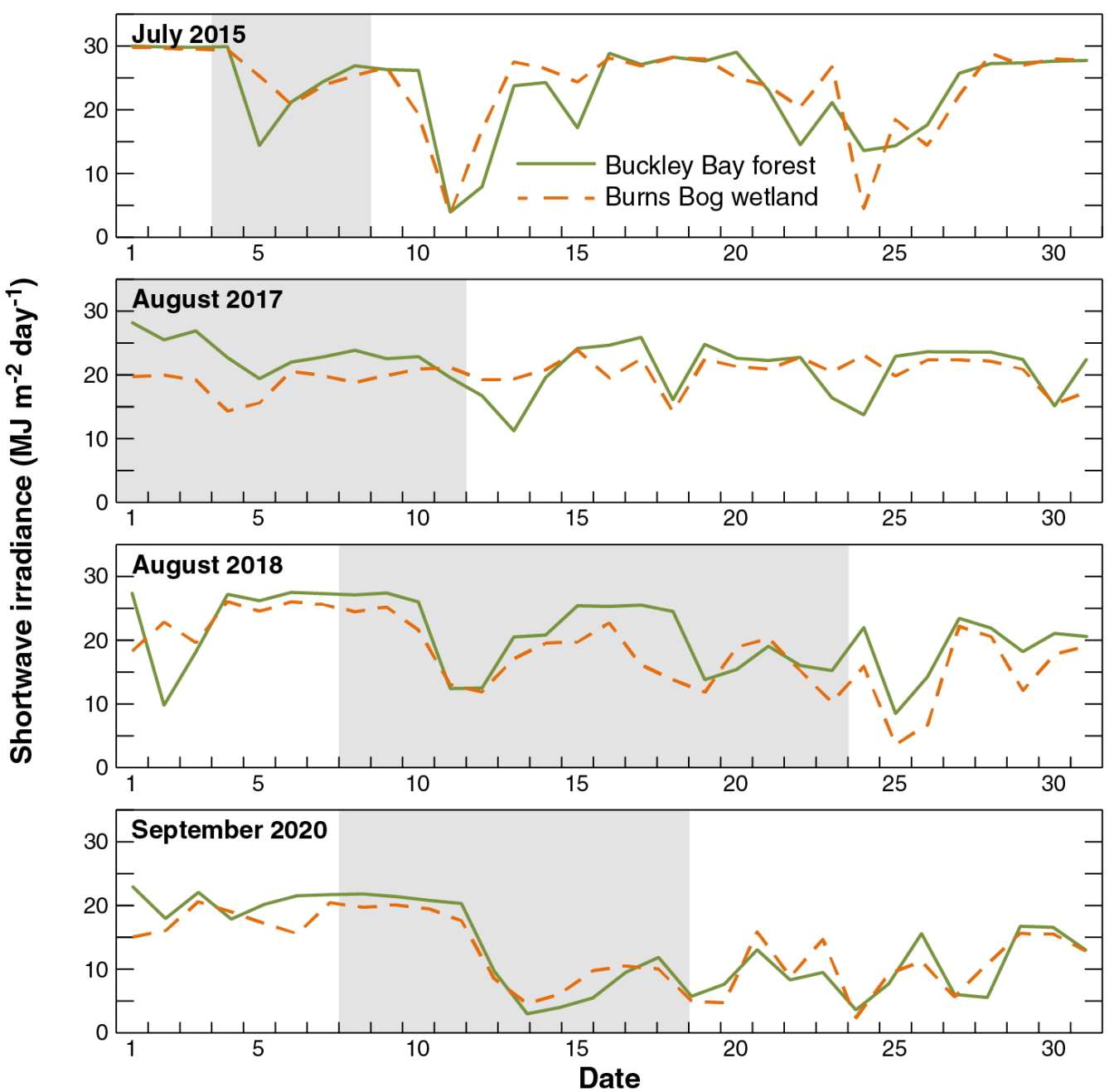

Figure S2. Daily shortwave irradiance over the wildfire smoke episodes (shaded) in 2015, 2017, 2018, and 2020 at Buckley Bay (the forest site) and at Burns Bog (the wetland site). 


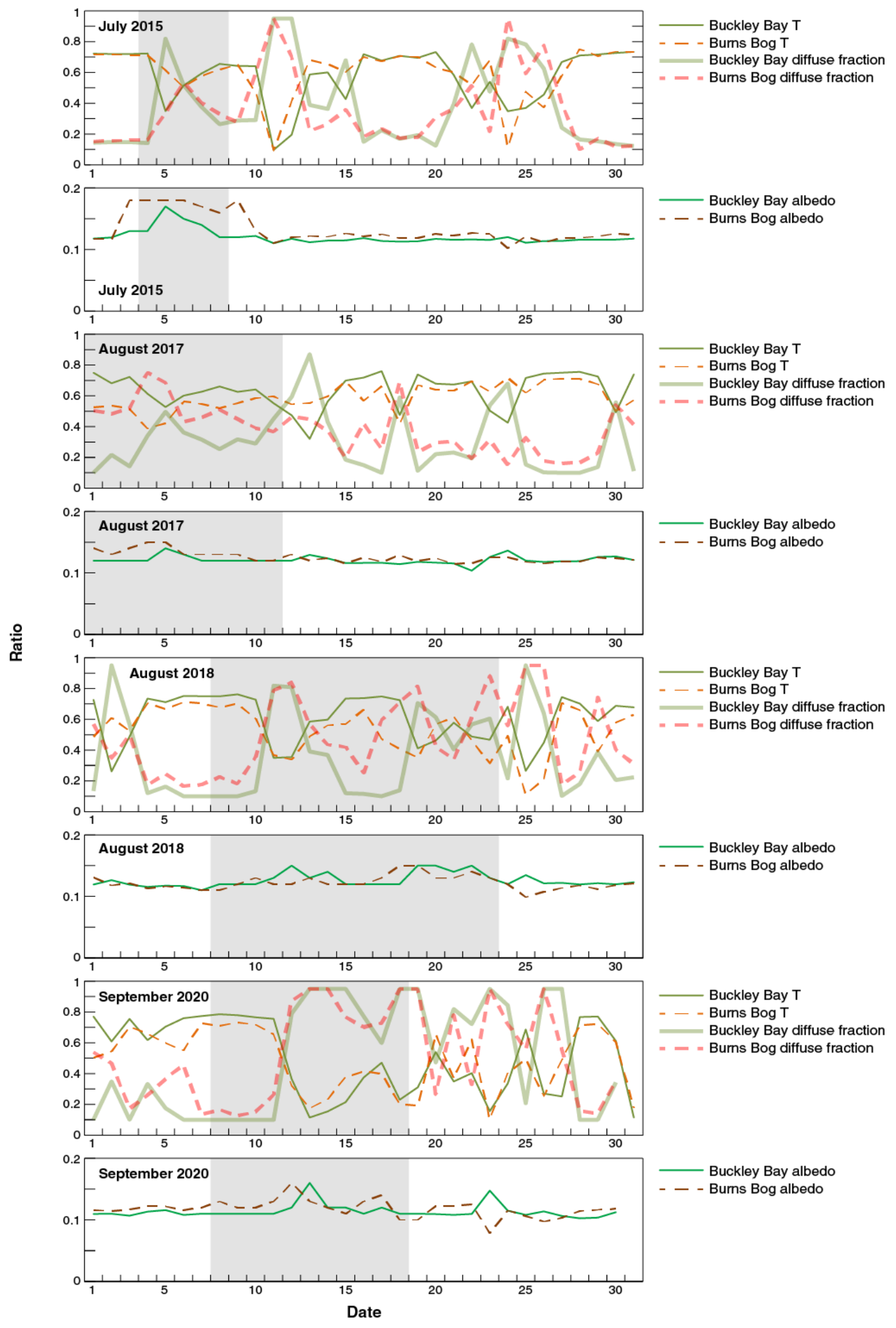

Figure S3. Daily averages of transmissivity $(T)$, albedo $(\alpha)$, and diffuse fraction of photosynthetically active radiation (PAR) (i.e., DF) at the forest and wetland sites during the smoke events (shaded) in 2015, 2017, 2018, and 2020. 


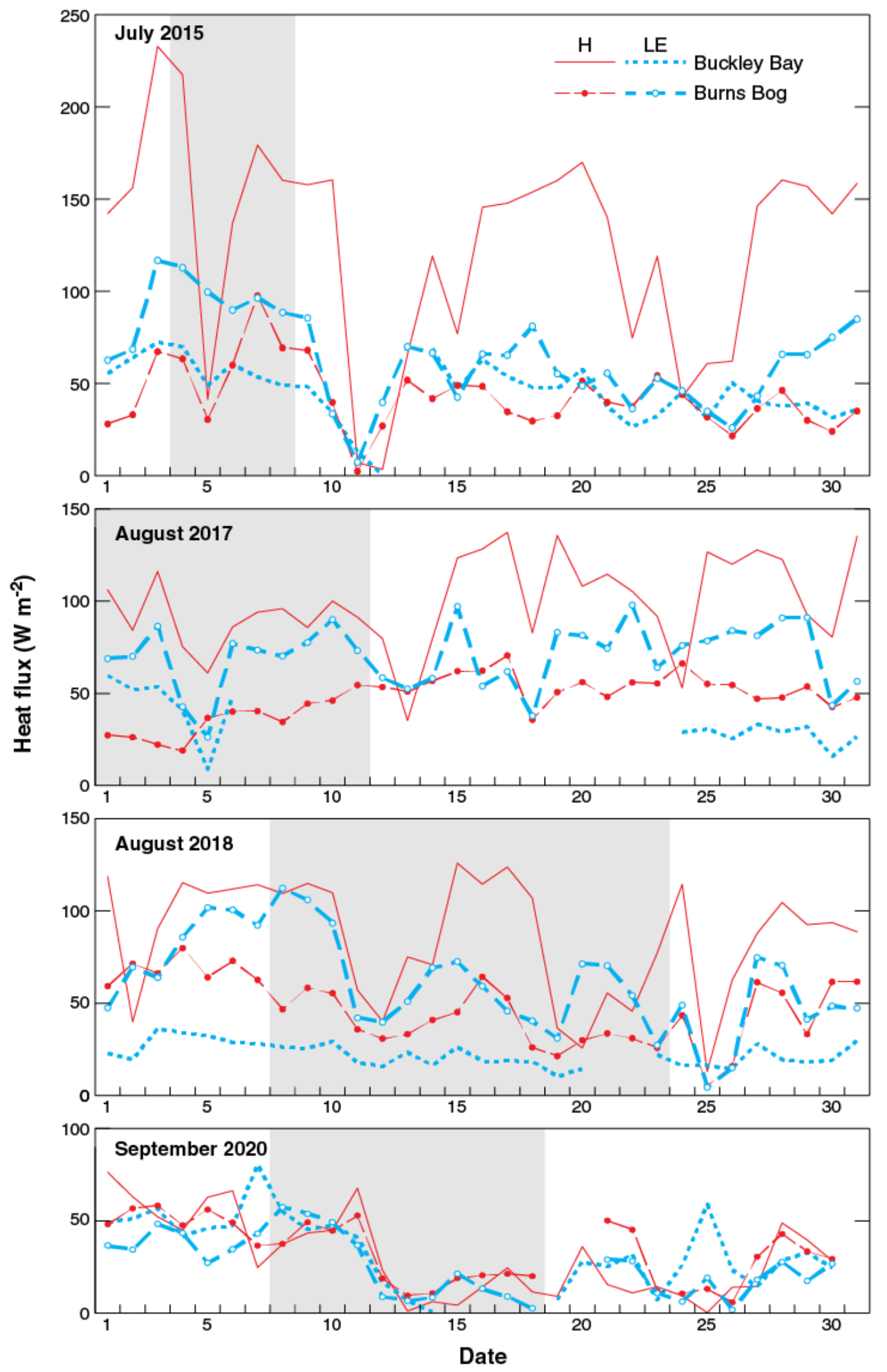

Figure S4. Daily (24-h) averages of sensible heat flux $(H)$ and latent heat flux $(L E)$ at the forest and wetland sites during the smoke events (shaded) in 2015, 2017, 2018, and 2020 . 


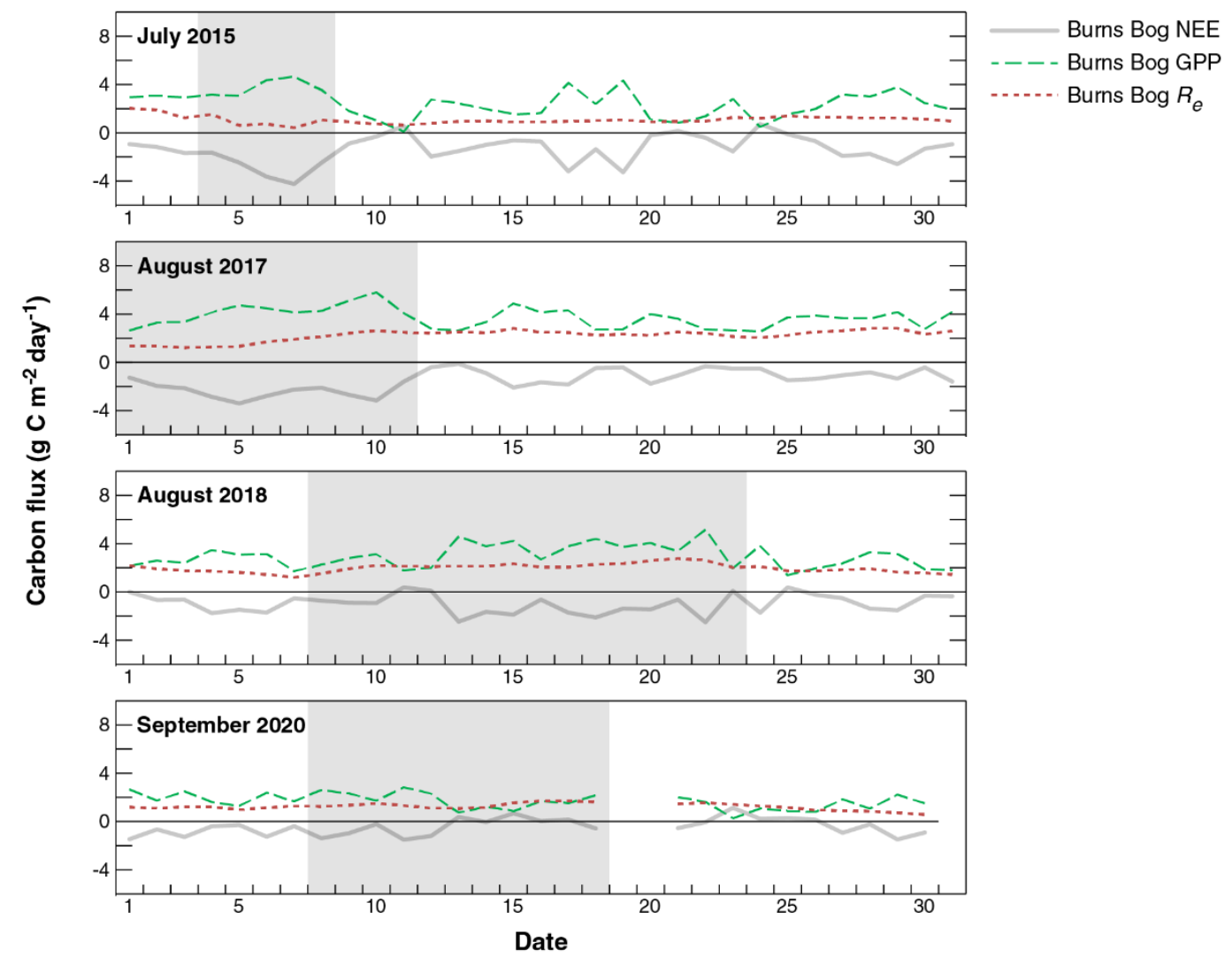

Figure S5. Daily totals of net ecosystem exchange (NEE), gross primary production (GPP), and ecosystem respiration $\left(R_{\mathrm{e}}\right)$ at the wetland site during the smoke events (shaded) in 2015, 2017, 2018, and 2020. 


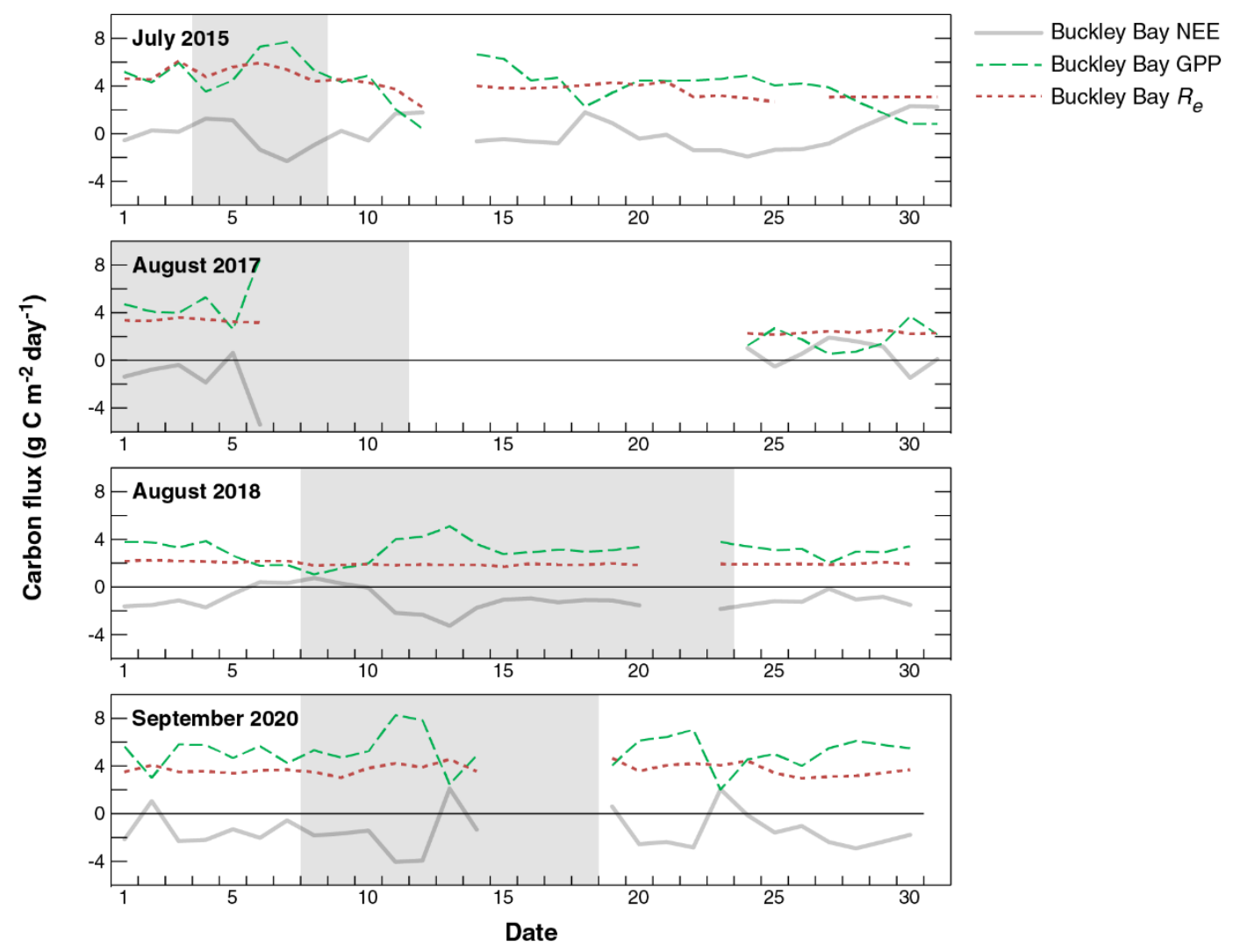

Figure S6. Daily totals of net ecosystem exchange (NEE), gross primary production (GPP), and ecosystem respiration $\left(R_{\mathrm{e}}\right)$ at the forest site during the smoke events (shaded) in 2015, 2017, 2018, and 2020. 